\title{
High-priority employment concerns of Hispanics/Latinos with multiple sclerosis in the United States
}

\author{
Richard T. Roessler ${ }^{\mathrm{a}}$, Phillip D. Rumrill, Jr ${ }^{\mathrm{b}, *}, \mathrm{Jian} \mathrm{Li}^{\mathrm{c}}$, Katherine Daly ${ }^{\mathrm{b}}$ and Karla Anhalt ${ }^{\mathrm{b}}$ \\ ${ }^{a}$ Independent Rehabilitation Consultant, Fayetteville, AR, USA \\ ${ }^{\mathrm{b}}$ Kent State University, Center for Disability Studies, Kent, OH, USA \\ ${ }^{\mathrm{c}}$ Kent State University, School of Foundations, Leadership, and Administration, Kent, OH, USA
}

Revised/Accepted August 2015

\begin{abstract}
.
BACKGROUND: Much of previous research on multiple sclerosis (MS) and employment has focused on people of European descent who acquire the disease, and very little is known about the experiences and concerns of people with MS from traditionally underrepresented racial and ethnic groups (e.g., African-Americans, Hispanics/Latinos), even though evidence indicates that the incidence of MS is increasing among non-Caucasians worldwide.

OBJECTIVE: The objective of this study was to identify high-priority employment concerns from Hispanics/Latinos with MS, whose needs for services and supports must be better understood to increase rehabilitation success of people with MS. METHODS: This article presents descriptive findings from a national survey of the employment concerns of Hispanics/Latinos with multiple sclerosis (MS; $N=206$ ). Representing nine chapters of the National Multiple Sclerosis Society, respondents were asked to evaluate 38 employment concerns items on two dimensions, importance and satisfaction, for the purpose of identifying strengths and weaknesses in the employment policies and practices affecting the labor force participation of people with MS.
\end{abstract}

RESULTS: Results revealed a total of 29 employment strengths and nine employment weaknesses.

CONCLUSION: Implications of these findings for rehabilitation policy and service delivery are examined.

Keywords: Multiple sclerosis (MS), Hispanic/Latino, employment

\section{Introduction}

The purpose of this article is to describe key factors that influence the employment outcomes of Hispanics/Latinos with multiple sclerosis (MS) and to recommend interventions to deal with those factors. In the past, much of the research on MS and employment has focused on people of European descent who acquire the disease. Very little is known about the experiences and concerns of people with MS from traditionally underrepresented racial and ethnic groups (e.g., African-Americans,

\footnotetext{
*Address for correspondence: Phillip D. Rumrill, Kent State University, P.O. box 5190, 413 White Hall, Kent, OH 44242-0001, USA. E-mail: prumrill@kent.edu.
}

Hispanics/Latinos), even though evidence indicates that the incidence of MS is increasing among nonCaucasians worldwide. Thus, the aim of this study was to identify high-priority employment concerns from the perspectives of a national sample of Hispanics/Latinos with MS, whose needs for services and supports must be better understood by rehabilitation professionals, employers, and other stakeholders in the rehabilitation success of people with MS.

\subsection{Multi-ethnic perspectives on multiple sclerosis}

Traditionally considered a chronic illness affecting mostly people of European lineage in the Northern 
Hemisphere, MS is now known to occur in all ethnic groups, with recent evidence documenting an increasing number of cases in Latin America. In the United States, although many similarities exist between Hispanics/Latinos with MS and European Americans with MS, some differences have been identified, suggesting the need for further study of this group. For example, age at onset of MS symptoms and age at diagnosis are slightly lower among Hispanics/Latinos (Amezcua, 2014). Given the fact that our limited knowledge of the experiences of Hispanics/Latinos with MS already suggests differences in comparison to the experiences of European-Americans, the important question asked by Vickers (2012, p.177), "what is life and work life really like for a person with MS?" should be extended to "what is life and work life really like for Hispanic/Latino persons with MS?"

The need for this study is further supported by the fact that much of the research-based knowledge on the impact of MS on employment relies on investigations in which the vast majority of participants are European American. For example, the percentages of participants of European extraction in MS employment-related research range typically from about $75 \%$ to $100 \%$ (Bishop et al., 2013; Chiu et al., 2013; Fraser et al., 2009; Julian et al., 2008; Rumrill, Roessler, \& Koch, 1999; Smith \& Arnett, 2005). Hence, information in this study is valuable because it is derived from the work-related perceptions of 206 Hispanic/Latino adults with MS, most of whom have work experience and many of whom are still employed.

\subsection{Cultural comparisons: some facts and assumptions}

Although little is known about how Hispanic/Latino adults with MS perceive their work lives, certain facts and assumptions do pertain to the question. First, the physical impact of MS on Hispanic/Latino individuals is very similar to that reported by European Americans. According to Amezcua (2014), Hispanic Whites and Non-Hispanic Whites report similar types of symptoms. Most Hispanics/Latinos are diagnosed with MS between the ages of 20 and 50, with diagnoses being most commonly conferred upon people in their $40 \mathrm{~s}$. Similar to European Americans with MS, the largest percentage of Hispanics/Latino adults with MS fall into the relapsing-remitting category, followed by the secondary progressive classification (Rivera \& Landero, 2005).
As to assumptions, this study presumes that the work role is important to Hispanic/Latino adults with MS and that conditions in the work environment influence their ability to secure, maintain, and progress in work. As Moore et al. (2013) and others (Sweetland et al., 2007) have noted, work is one of the most central commitments among Western populations, providing not only access to financial remuneration and security but also a sense of identity and selfesteem. Furthermore, it is assumed that the symptoms associated with MS (e.g., fatigue, weakness, cognitive problems, and higher pain levels) significantly impede the ability of Hispanic/Latino individuals diagnosed with the disease to succeed in the workplace (Moore et al., 2013) and that the responsiveness to symptoms of MS within the work environment is a significant predictor of employment retention. For example, in their research, Uccelli et al. (2009) found that aspects of the work environment directly influenced the employment retention of adults with MS. People with MS who were more likely to maintain employment experienced certain facilitating conditions such as physical accessibility, flexible work schedules, and time off as needed. It is reasonable to expect that these findings would hold among Hispanics/Latinos with MS.

For all that is known about the factors associated with labor force participation among people with MS in general, very little is known about the employment experiences and concerns of the growing population of Hispanics/Latinos in the United States who are coping with this unpredictable and highly intrusive disease. Findings from this study fill an important gap in the knowledge base, providing a contemporaneous view of strengths and weaknesses in employment policies and practices and, thus, of the priorities for employment agenda planning so that more Hispanics/Latinos with MS can participate in the workforce.

\subsection{Research questions}

The research questions for this investigation were as follows:

1. What are the most important employment concerns from the perspectives of Hispanics/Latinos with MS?

2. What are the important employment concerns with which Hispanics/Latinos with MS are most satisfied (i.e., what are the strengths in employment policies and practices)? 
3. What are the important employment concerns with which Hispanics/Latinos with MS are least satisfied (i.e., what are the weaknesses in employment policies and practices)?

\section{Methods}

The authors implemented a Participatory Action Research (PAR; Graves, 1991) methodology to survey the employment concerns of people with MS. A sub-sample of Hispanic/Latino respondents was drawn to answer the specific research questions for this investigation. National Multiple Sclerosis Society (NMSS) chapters throughout the United States participated in various phases of the study, beginning with survey construction and ending with responding to the survey in paper-and-pencil, online, or telephone administrations. Thus, the survey itself and the resulting profile of employment strengths and weaknesses among Hispanics/Latinos with MS are thoroughly grounded in the perspectives of people with MS.

\subsection{Participants}

The respondent sample for this investigation consisted of 206 Hispanics/Latinos with MS, 50 men $(24.3 \%)$ and 156 women $(75.7 \%)$. About thirty-nine percent $(38.8 \%)$ of respondents described their communities as suburban, whereas 55.1 percent lived in urban areas and 6.1 percent resided in rural settings. The sample reported a mean age of 48.74 years ( $\mathrm{SD}=12.69$ years). Less than forty-four percent $(43.2 \%)$ of respondents were employed for pay at the time of the survey, with 36.4 percent of respondents reporting full-time employment and 6.8 percent reporting part-time hours. Twenty-one employed respondents $(23.6 \%)$ indicated that they had requested workplace accommodations from their employers, and 39 employed respondents (43.8\%) reported using workplace accommodations at the time of the survey. The most commonly used types of workplace accommodations were changes in work schedules (used by $20.2 \%$ of employed respondents), followed in descending order of frequency by changes in job duties/procedures (12.4\%), modifications of work stations or company physical facilities $(6.7 \%)$, work at home part of the time (6.7\%), modification of equipment (5.6\%), reassignment to another position (3.4\%), driver (3.4\%), work at home all of the time (3.4\%), installation of new assistive equipment (2.2\%), and personal care assistant (2.2\%).
The sample was an experienced (84\% had employment histories and $81 \%$ were still working at the time of diagnosis) and well-educated group of workers $(90.3 \%$ were high school graduates and $36.9 \%$ were college graduates). More than half of the sample were dealing with the relapsingremitting form of MS (54.4\%), and the mean number of reported MS symptoms was $7.60(\mathrm{SD}=4.14)$. In descending order of frequency, the most commonly reported symptoms were fatigue (reported by $72.8 \%$ of the sample), diminished physical capability $(62.1 \%)$, balance/coordination problems $(57.3 \%)$, tingling in the extremities (49.5\%), gait/mobility problems $(48.5 \%)$, cognitive impairment $(48.1 \%)$, bowel/bladder dysfunction (45.1\%), pain (44.7\%), numbness $(44.7 \%)$, spasticity $(43.7 \%)$, sleep disturbance $(40.3 \%)$, depression $(39.8 \%)$, anxiety (36.9\%), vision problems (34.5\%), sexual dysfunction $(32.5 \%)$, speech problems $(21.4 \%)$, tremor $(17.5 \%)$, and bipolar disorder (5.8\%).

\subsection{Instrument}

The instrument used in the survey was a 98 -item questionnaire that included fixed and open response sets. Components of the survey used in this investigation included sections on participant demographics, work history and employment activities, illnessrelated variables, and 38 employment concerns items. The 38 employment concerns items were the primary focus of this study. In responding to those items, individuals indicated whether they considered the concern to be important and whether they were satisfied that the concern was being addressed in their communities. Concerns items addressed such issues as access to information on disability benefits programs, discrimination in hiring and retention practices of employers, employment protections under major legislation, the quality of rehabilitation and employment services, access to assistive technology, and support for returning to work and planning for the future.

\subsection{Procedure}

In developing the employment concerns section of the survey, the authors consulted with 13 people with MS who were members of one NMSS chapter in the Midwestern United States. In a three-hour working group session, these consumers reviewed a pool of 157 employment practice and policy-related items to select the 38 they considered most relevant to people 
with MS. Working group members were also encouraged to nominate additional items for the survey, but the group reported that the items in the pool, with minor editing, adequately covered their concerns.

After preparing the survey based on the input of people with MS, the researchers asked a panel of MS experts to review the instrument for readability and content coverage. Following final revision of the questionnaire, the researchers identified, with the assistance of the NMSS, nine chapters to participate in the study. These chapters were selected because they provided a strong representation of geographic areas, rural/urban/suburban settings, and diverse racial/ethnic groups.

The original target sample for this investigation included 8,000 people with MS representing the 9 chapters. As a means of ensuring adequate representation of Hispanic/Latino and African-American respondents, the researchers oversampled members of those two groups within NMSS chapters that had relatively high proportions of Hispanics/Latinos and African-Americans on their client registries. Eight of the participating NMSS chapters were asked to identify stratified random sub-samples of 800 clients (stratified by racial/ethnic backgrounds depending upon the representation of Hispanics/Latinos and African Americans in their client registries), and one chapter was asked to draw a stratified random subsample of 1,600 clients - 100 African Americans, 800 Hispanics/Latinos, and 700 clients from other racial and ethnic backgrounds. The goal of this sampling procedure was to ensure that at least five percent of the overall respondent sample was Hispanic/Latino and that at least five percent was African American; these proportions are consistent with commonly held estimates of population parameters for people with MS (Minden et al., 2006). Within the stratified random target sample of 8,000 people with MS, 1,123 (14\%) were Hispanic/Latino and 603 (7.5\%) were African American. The remaining 6,274 members of the target sample represented all other racial and ethnic backgrounds in the NMSS' client data tracking system.

Once the sampling plan was finalized, the authors prepared the survey questionnaire for distribution by each of the chapters. Two weeks prior to mailing the questionnaires, chapter service directors sent a prenotice letter (Dillman, 2007) to those selected for the national survey $(N=8,000)$. The pre-notice letter explained the purpose of the study and the importance of completing and returning the survey. The survey was then mailed with another explanatory cover letter from the project director. The cover letter provided instructions for completing the questionnaire in hard copy, online, or via telephone depending upon the preferences of the respondent. Four weeks after the survey had been mailed, the authors provided the chapters with 'reminder/thank you' postcards (Dillman, 2007) to send to the 8,000 people who received the questionnaire. In a final effort to increase survey return rates, participating NMSS chapters sent an email "blast" to the target sample six weeks after the reminder/thank you postcards had been delivered.

All correspondence concerning the survey with NMSS members who identified themselves as Hispanic/Latino was provided in both Spanish and English. Specifically, the pre-notice letter, the explanatory cover letter, the survey questionnaire, and the reminder/thank you postcard were first developed in English and then translated into colloquial Spanish by a bilingual Spanish-English interpreter/translator who is frequently retained by chapters of the NMSS. After translating the original versions of all correspondence to Spanish, the interpreter/translator consulted another bilingual NMSS staff member who translated the Spanish versions of materials back into English to ensure the bi-directional accuracy of translated documents. Therefore, all Spanish study materials were developed through a back-translation process (Knight et al., 2009). All members of the target sample who self-identified as Hispanic/Latino received both English and Spanish versions of all documents. Furthermore, the interpreter/translator was retained to administer the survey via telephone to all Hispanic/Latino respondents who preferred a telephone administration of the survey and who indicated a preference for a Spanish-speaking interviewer.

Six hundred thirty-one surveys were returned to participating chapters as undeliverable, reducing the available target sample to 7,369 people with MS. Of the available target sample, 1,932 members returned questionnaires, resulting in a response rate of $26 \%$. Two hundred and six respondents (10.7\%) identified themselves as Hispanic/Latino and were included in the present analysis.

\subsection{Data analysis}

Descriptive statistics such as frequencies and percentages were used to answer the three research questions. For each of the 38 employment concerns items, an Importance rating was calculated as the percentage of respondents who evaluated the item 
as important. Likewise, each item was also assigned a Satisfaction rating that was calculated as the percentage of respondents who were satisfied with the current status of that item. An employment strength was defined as an item with a high Importance rating (i.e., greater than 60 percent) and a high Satisfaction rating (i.e., greater than 60 percent). An employment weakness was defined as an item with a high Importance rating (i.e., greater than 60 percent) and a low Satisfaction rating (i.e., less than 60 percent).

\section{Results}

The first research question addressed the importance ratings that respondents assigned to each item. Support for the PAR approach to instrument development whereby a working group of people with MS helped researchers to identify the 38 employment concerns items is evident in the fact that all 38 items were evaluated as important by about three quarters of the sample (the lowest importance rating was $74.9 \%$ ), and 37 of the 38 items had importance ratings of at least 80 percent. Table 1 lists the 38 employment concerns items for Hispanic/Latino participants in descending order of importance ratings.

The second research question addressed the perceived strengths in employment policies and practices from the vantage point of Hispanics/Latinos with MS. Defining a strength as an item with an importance rating of at least 60 percent and a satisfaction rating of at least 60 percent, the researchers identified a total of 29 strengths. Table 2 presents these strength items in descending order of their satisfaction ratings.

The third research question addressed perceived employment weaknesses from the point of view of Hispanic/Latino survey respondents. The researchers defined a weakness as an item with an importance rating of at least 60 percent and a dissatisfaction rating of at least 40 percent. By that definition, nine employment concerns items qualified as weaknesses. Table 3 presents the nine weakness items in descending order of their dissatisfaction ratings.

\section{Discussion}

Initially, it is important to note that all 38 employment concerns included in the survey were evaluated as important by at least 74 percent of the sample, and 37 of the 38 were evaluated as important by at least 80 percent of the sample. This result is supportive of the
PAR approach to instrument development whereby 13 members of the NMSS identified the 38 highestpriority employment issues facing Americans with MS.

Hispanic/Latino respondents were satisfied with 29 of the 38 items in the employment concerns survey and dissatisfied with only nine items, which is somewhat surprising given their low rate of labor force participation. For purposes of discussion, we divided the 38 employment concerns into two categories; significant strengths (importance ratings greater than $60 \%$ and satisfaction ratings higher than $60 \%$ ) and significant weaknesses (importance ratings greater than $60 \%$ and dissatisfaction ratings greater than $40 \%$ ). The resulting groups of items (i.e., strengths and weaknesses) suggest two strategies for human service and advocacy organizations. Significant strengths represent agenda items requiring "preserve and protect" action plans. Significant weaknesses represent agenda items requiring "remediate or resolve" action plans.

\subsection{Significant strengths}

The most prominent employment strengths for Hispanic/Latino adults with MS cluster into themes such as personal control and expectations of others, employee benefits, communication with employers, equitable workplace policies and fair treatment, physical accessibility of the work place, performance evaluation, access to service providers, Social Security and disability benefits, training and advancement, and health insurance coverage. The predominance of strengths in this survey of Hispanic/Latino adults with MS contrasted sharply with results from a similar concerns report study conducted in 2002 with a multi-ethnic national sample of 1,310 people with MS (Roessler, Rumrill, \& Hennessey, 2002) prior to implementation of the Americans with Disabilities Act Amendments Act (ADAAA) and the Affordable Care Act (ACA). Respondents in the Roessler et al. (2002) survey identified only three employment strengths and 29 employment weaknesses. Although encouraging, the optimism revealed in the present study about employment issues pertaining to discrimination on the job, support from others to continue employment, and physical accessibility seems inconsistent with the fact that only about two-fifths (43.2\%) of respondents were employed at the time of the present study. In fact, the rate of employment among Hispanic/Latino participants in this study is about the same as those reported in the original concerns 
Table 1

Employment concerns items and their importance ratings

\begin{tabular}{|c|c|}
\hline Item & $\%$ Importan \\
\hline \multicolumn{2}{|l|}{ People with MS ... } \\
\hline Have access to service providers who understand the needs of people with MS. & 97.8 \\
\hline Have access to health insurance when changing jobs or returning to a previous job. & 97.8 \\
\hline Are provided the same retirement benefits as other workers. & 97.3 \\
\hline Are encouraged to take control of their lives. & 97.2 \\
\hline Understand the risks and benefits of disclosing disability status to employers. & 97.2 \\
\hline Receive the same severance pay as other workers. & 96.7 \\
\hline Have adequate information about benefits such as health and disability (short and long-term) insurance. & 96.7 \\
\hline Have the same opportunity for promotion as other workers. & 96.7 \\
\hline Know what to do if they encounter discrimination at work. & 96.7 \\
\hline Are made aware of employer expectations in the same way as other employees. & 96.7 \\
\hline Have adequate health insurance coverage. & 96.2 \\
\hline Receive the same on-the-job training opportunities as other workers. & 96.2 \\
\hline Understand the employment protections of Title I in the Americans with Disabilities Act as Amended (ADA). & 96.1 \\
\hline Have access to adequate information about Social Security programs. & 95.6 \\
\hline Have their seniority honored in the same way as other employees. & 95.6 \\
\hline Can expect employers to respect their privacy regarding health and disability-related information. & 95.6 \\
\hline Understand the health insurance provisions and protections of the Affordable Care Act (i.e., Obamacare). & 95.6 \\
\hline Have the same maternity and family leave options as other workers. & 95.6 \\
\hline Know their rights regarding job-related physical examinations. & 94.6 \\
\hline Have access to assistive technology resources needed for work. & 94.5 \\
\hline Are recalled from layoffs in the same manner as other workers. & 94.5 \\
\hline Make the decision to quit or retire without being pressured or forced to do so by employers. & 93.9 \\
\hline Are evaluated based on their performance, not on assumptions about MS. & 93.9 \\
\hline Can request a review of their accommodation needs without fear of retaliation. & 93.4 \\
\hline Have physical access to workplace facilities. & 93.0 \\
\hline Are treated fairly in termination or demotion decisions made by their employers. & 92.9 \\
\hline Are not subjected to harassment or intimidation in the workplace because of their MS. & 92.8 \\
\hline Can expect employers to respond to their accommodation needs in a timely manner. & 92.4 \\
\hline Have access to the full range of employment opportunities offered by their employers. & 92.4 \\
\hline Know how to discuss their job accommodation needs with employers. & 92.0 \\
\hline Are treated fairly by employers in the hiring process. & 91.9 \\
\hline Are considered for other jobs in the same company if their MS prevents them from returning to their former jobs. & 91.3 \\
\hline Have opportunities for job training or retraining. & 90.3 \\
\hline Have their qualifications for employment and advancement fairly evaluated by employers. & 90.1 \\
\hline Are evaluated no more frequently than other workers. & 88.5 \\
\hline Are given references from past employers based on work performance, not on disability status. & 86.8 \\
\hline Are asked interview questions related to job tasks and personal qualifications rather than to health and disability matters. & 84.4 \\
\hline Are expected, by their physicians and significant others, to remain employed after diagnosis. & 74.9 \\
\hline
\end{tabular}

report survey (Roessler et al.) and in other MS research (e.g., Bishop et al., 2013; Julian et al., 2008; Moore et al., 2013). Thus, these findings may suggest, in part, alternative explanations for the high jobless rates among Hispanic/Latino adults with MS such as education level, fatigue related to job duties and roles, and overall progression in disability level, particularly in terms of cognitive limitations (Honarmand et al., 2011; Krause, Kern, Horntrich, \& Ziemssen, 2013; Moore et al, 2013; Simmons, Tribe, $\&$ McDonald, 2010). Others have cited different nonworksite factors as central to leaving the work force such as disincentives in disability benefits programs (Marini, 2003) and more subtle and difficult to verify forms of workplace discrimination (Rumrill et al., 2005).
Nevertheless, rehabilitation professionals should not lose sight of one conclusion from Phillips and Stuiefbergen's (2006) research: improved employment retention for adults with MS requires attention to both personal and workplace considerations, a proposition that is supported in the employment weakness findings in this study. Although historically underserving people with MS (Johnson et al., 2004), the State-Federal Vocational Rehabilitation (VR) program has the capabilities to address both person and environment issues via physical restoration and on-the-job intervention services, thereby becoming one agency working to preserve the employment strengths reported in this study (Chiu et al., 2013; Johnson et al., 2004; Nissen \& Rumrill, 2014). Advocacy organizations such as the National Multiple 
Table 2

Employment strengths

Item $\%$ Satisfied

People with MS ...

Are encouraged to take control of their lives.

Are provided the same retirement benefits as other workers.

Are given references from past employers based on work performance, not on disability status. 75.3

Receive the same on-the-job training opportunities as other workers.

Have their seniority honored in the same way as other employees. 74.8

Are evaluated no more frequently than other workers.

Have the same maternity and family leave options as other workers.

Are made aware of employer expectations in the same way as other employees.

Have physical access to workplace facilities. 69.9

Receive the same severance pay as other workers. $\quad 69.6$

Can expect employers to respect their privacy regarding health and disability-related information. 69.1

Have access to service providers who understand the needs of people with MS. 69.0

Are asked interview questions related to job tasks and personal qualifications rather than to health and disability matters. $\quad 69.0$

Are not subjected to harassment or intimidation in the workplace because of their MS. 69.0

Have their qualifications for employment and advancement fairly evaluated by employers. 66.7

Are treated fairly by employers in the hiring process. 66.5

Have the same opportunity for promotion as other workers. 66.2

Make the decision to quit or retire without being pressured or forced to do so by employers.

Are treated fairly in termination or demotion decisions made by their employers.

Know their rights regarding job-related physical examinations. 64.6

Are expected, by their physicians and significant others, to remain employed after diagnosis. 64.3

Have opportunities for job training or retraining.

Are recalled from layoffs in the same manner as other workers.

Have access to adequate information about Social Security programs. 62.5

Are evaluated based on their performance, not on assumptions about MS. 61.9

Have access to health insurance when changing jobs or returning to a previous job. 61.7

Have adequate health insurance coverage. 61.4

Understand the employment protections of Title I in the Americans with Disabilities Act as Amended (ADA). 60.8

Know what to do if they encounter discrimination at work.

Table 3

Employment weaknesses

Item

$\%$ Dissatisfied

People with MS...

Know how to discuss their job accommodation needs with employers.

Are considered for other jobs in the same company if their MS prevents them from returning to their former jobs. 44.2

Understand the health insurance provisions and protections of the Affordable Care Act (i.e., Obamacare). 43.3

Can expect employers to respond to their accommodation needs in a timely manner. 43.0

Can request a review of their accommodation needs without fear of retaliation. 40.9

Have access to assistive technology resources needed for work. 40.6

Have access to the full range of employment opportunities offered by their employers. 40.6

Have adequate information about benefits such as health and disability (short and long-term) insurance. 40.4

Understand the risks and benefits of disclosing disability status to employers.

Sclerosis Society contribute to preserving strengths, as well, both by advocating with employers on behalf of adults with MS and by teaching employees with MS how to address their job-related needs as their conditions change (Antao et al., 2013; Uccelli et al., 2009). Adults with MS and rehabilitation professionals have also called for more direct intervention at the worksite in the form of a job specialist whose role is to help employees with MS confront employment discrimination and implement job accommodations
(Neath et al., 2007; Sweetland et al., 2007). Finally, the Equal Employment Opportunity Commission (EEOC) plays a strong role in rectifying business practices antithetical to preservation of employment strengths. The Commission's well established allegation and resolution practices are accessible to individuals in all racial/ethnic groups and serve to protect charging parties from discriminatory practices included in the employment strengths in this study (Neath et al., 2007). 


\subsection{Significant weaknesses}

Nine employment weaknesses (importance rating $>60 \%$, dissatisfaction rating $>40 \%$ ) appeared in the item ratings from Hispanic/Latino respondents. Employment weaknesses pertain to the following four broad topics: job accommodations, insurance benefits, employment options, and disclosure. Employment weaknesses in the job accommodation domain pertain to knowing how to request accommodations in order to gain access to assistive technology in a timely manner without provoking retaliatory measures from employers. Insurance benefits relate to perceived information deficits regarding health and disability insurance, particularly the Affordable Care Act (ACA). Employment weaknesses regarding job options were of two types, specifically not being considered for job reassignment if one could not return to his or her previous job due to MS symptoms and not having access to the full range of employment opportunities offered by one's employer. The final weakness addressed lack of knowledge about the risks and benefits of disclosing disability status to one's employer.

Before discussing these employment weaknesses individually, it is important to note that the StateFederal VR program provides services responsive to the majority of them. In a recent article, Chiu et al. (2013) reported on the results of a prediction study using information about VR consumers with MS in the Rehabilitation Services Administration's 911 database. Pertinent to each of the discussions to follow, the five VR services that were most strongly related to achieving competitive employment in an integrated community setting included counseling and guidance; job placement assistance; on-the-job supports; assistive technology services; and maintenance support for food, shelter, clothing, and transportation.

\subsubsection{Job accommodations}

Four of the employment weaknesses pertained to deficiencies that respondents experienced regarding how to discuss their needs for on-the-job accommodations, how to access those accommodations in a timely manner, how to access assistive technology on the job, and how to request job accommodations without fear of retaliation. Techniques for discussing needs for accommodations do exist that have the potential to improve the timeliness of implementation of accommodations including assistive technology (Roessler \& Rumrill, 2015). The key to the process is preparation on the part of the employee, who should approach the discussion in a positive way (e.g., "I have some ideas about how I can be even more productive with your help") with some ideas about the type of accommodation needed (e.g., "I have done some research and have ideas about what might work, what it might cost, and who could provide it"). Even though employers have the final say in the accommodation selected, they are required to enter into an interactive discussion with the employee and to offer alternative options to increase the person's productivity (The HR Specialist, 2013).

Resources such as the Job Accommodation Network (AskJan.org, 800-526-7234 (voice), 877781-9403 (TTY), the National Multiple Sclerosis Society, and the State-Federal VR Agency are available to suggest accommodation ideas, negotiation techniques with employers, and sources for accommodations. Both the Job Accommodation Network and the National MS Society have a wide array of documents and support available in Spanish, so Hispanic/Latino workers with MS can be alerted to these resources if they prefer information in Spanish. Beneficial accommodations for adults with MS include physical access, flexible work schedules and breaks, sedentary work, co-worker assistance with certain tasks, and assistive technology (Johnson et al., 2004).

Hopefully, when approached in a positive way, the request for an accommodation should not result in employer resistance and retaliation. However, the employee with MS in need of an accommodation does have some protections against such reactions. Implemented in 2009, the Americans with Disabilities Act Amendments Act (ADAAA) continues the long standing emphasis of the ADA on the right of individuals with disabilities who are otherwise qualified for a position to request and use reasonable accommodations on the job. In fact, the ADAAA reinforces this right and simplifies its application by naming MS as a chronic health condition covered under the Act and by underscoring the employer's obligation to avoid discriminating against workers who request and merit such an accommodation.

Results of this study suggest that Hispanics/Latinos with MS could benefit from information about the ADAAA and its provisions that is presented in both Spanish and English. Culturally authentic self-advocacy training regarding how to identify, request, and implement on-the-job accommodations is another potentially important strategy for remedying the accommodation-related weaknesses identified in this investigation. 


\subsubsection{Insurance benefits}

Accessible, bilingual information concerning the ACA could enhance awareness of health insurance benefits and protections among Hispanic/Latino people with MS, thereby ameliorating the weakness associated with health insurance coverage in general and the ACA in particular. Hispanics/Latinos with MS could find this information more effectively if individuals hired as ACA Navigators and ACA websites were informative, user-friendly, culturally sensitive, and easily accessed resources. Hispanics/Latinos (and others) with MS need to know that the ACA (a) requires employers to provide group health insurance coverage for employees who work at least 30 hours per week, (b) prohibits health insurance companies from excluding people from coverage based on pre-existing conditions, and (c) prohibits health insurance companies from imposing annual or lifetime "caps" on coverage (Wickert, Dresden, \& Rumrill, 2013).

Bilingual outreach, advocacy, and direct service efforts to help Hispanic/Latino adults with MS understand their health insurance options and access quality health care are an important adjunct to state VR and other employment-related services for people with MS. Physicians, social workers, nurses, counselors, and rehabilitation professionals alike must be well versed in the provisions of the ACA, and they must make concerted efforts to communicate those provisions to adults with MS in the Hispanic/Latino community. This requires coordination with indigenous leaders in that community, provision of authentically translated English-to-Spanish and Spanish-to-English materials, and availability of bilingual staff members to provide support.

\subsubsection{Job options}

Lack of access to the full range of employment opportunities offered by employers was a prominent area of dissatisfaction for more than $40 \%$ of the Hispanic/Latino respondents. To improve that situation, personnel and human resource departments should improve their outreach and communication efforts, recognizing the need to communicate some of this information in Spanish. Employers should also make concerted efforts to reach out to Hispanic/Latino employees with MS to encourage their enrollment in on-the-job training, career exploration, and promotion and advancement counseling.

Although dissatisfied with opportunities for job reassignment in response to limitations from MS, Hispanic/Latino adults with MS need to realize that reassignment is typically considered a job accommodation of last resort in the ADA and by the Equal Employment Opportunity Commission (EEOC; Taylor, 2007). Moreover, requests for reassignment are met with more employer resistance than any other accommodation option identified by workers with MS (Rumrill, Fraser, \& Johnson, 2013). Therefore, rehabilitation professionals must work closely with employees and employers to consider whether other types of accommodations might enable the individual to continue in his or her original position. If reassignment is contemplated, support personnel must consider the implications for any existing collective bargaining agreements or other employee policies. When the worker is reassigned to another position, support must be provided to help the worker adjust to his or her new job, including any accommodations that would aid in the performance of job tasks. The employer is, however, not required to retrain the employee for the position but is responsible to suggest appropriate reassignment options (e.g., a position of equal pay and status if available) for the individual (Taylor, 2007).

\subsubsection{Disclosure}

The dilemma of disclosure was faced by $40 \%$ of the Hispanic/Latino participants in that they are dissatisfied with their understanding of the risks and benefits of disclosing their disability to their employers. The benefits of disclosure are clear in that disclosure of disability is the first step in acquiring the protections in the ADAAA pertaining to nondiscrimination and accommodation. The drawback of disclosure is that it, in some cases, may result in stigmatizing the employee with a disability in the eyes of co-workers and employers. Manifestations of stigma on the employer's part include immediate assumptions that the person's performance will deteriorate now and/or in the future and that expensive supports are required in terms of assistive technology and physical accessibility (Vickers, 2012). Countering these risks, the protections of the ADAAA are invoked once individuals disclose the existence of a disability and their need for job accommodations.

Because of the complexity of the disclosure situation, Sweetland et al. (2007) recommended the involvement of a work specialist therapist available via self-referral on the part of the employee with MS. Support from such a specialist is invaluable in cases where evidence exists of discrimination on the part of the employer, and employee self-advocacy 
is required to pursue the allegation, which, in the case of workers with MS, typically concerns either unlawful discharge or failure to provide a reasonable accommodation (Neath et al., 2007). This specialist is also a knowledgeable resource who could not only help the employee with MS develop an accommodation request approach but also educate employers regarding the nature of MS and their responsibilities under the ADAAA. Here again, to most effectively assist Hispanic/Latino individuals with MS in the often complicated process of disability disclosure, the specialist must be culturally competent regarding Hispanic/Latino community norms related to interpersonal communication, making requests of others, and interacting with supervisors and other authority figures.

\section{Conclusion}

The purpose of this article was to describe the highest priority strengths and weaknesses in existing employment policies and services as identified by a targeted sample of Hispanic/Latino adults with MS $(N=206)$. Of the 38 employment concerns in the survey, 29 met the criteria for employment strengths, and nine met the criteria for employment weaknesses. Still, only 43 percent of the respondent sample was employed at the time of the survey, which raises some question as to why respondents were satisfied with 29 of the 38 employment concerns items. Possibly, many of those who were not currently working attributed their unemployment more to MS symptoms (e.g., fatigue, weakness, and cognitive limitations) than to workplace factors such as employment discrimination.

Nevertheless, results of the study did point to significant areas of concern pertaining to workplace factors with negative effects on the job retention of Hispanic/Latino employees with MS. Participants lacked confidence in their ability to manage the disclosure and accommodation process set forth in the Americans with Disabilities Act, which suggests that, irrespective of their apparent satisfaction with most of the employment concerns, they did anticipate the possibility of discrimination on the part of employers. They were dissatisfied with their access to career options offered by their employers and with implementation of reassignment as a reasonable accommodation. Finally, participants needed more information about health and disability benefits, particularly the Affordable Care Act.
Addressing these employment concerns by preserving the strengths and reducing or removing the weaknesses will contribute to greater job retention on the part of Hispanic/Latino adults with MS. Some of the strategies needed require changes in service delivery; others require changes in employer attitudes and behavior. Some even require changes at the level of social policy and beliefs. Regardless of the change level, implementation and evaluation of the "preserve and protect" and "reduce or remove" interventions will result in greater job and life satisfaction for the growing population of Hispanic/Latino adults with MS. It will also result in greater productivity of the American workforce given the talents and expertise of this group of experienced, well-educated individuals.

\section{Acknowledgments}

This research was funded through a Health Care Delivery and Policy Research grant from the National Multiple Sclerosis Society, New York, NY. The authors wish to thank the National Multiple Sclerosis Society, its participating chapters, and the study participants for their support and assistance with this research.

\section{Conflict of interest}

The authors have no conflict of interest to report.

\section{References}

Amezcua, L. (2014). Multiple sclerosis in the Latino/Hispanic American. Los Angeles, CA: Keck Medical School, University of Southern California.

Antao, L., Shaw, L., Ollson, K., Reen, K., To, F., Bossers, A., \& Cooper, L. (2013). Chronic pain in episodic illness and its influence in work occupations. Work: A Journal of Prevention, Assessment, and Rehabilitation, 44, 11-36.

Bishop, M., Roessler, R., Rumrill, P., Frain, M., Waletich, B., \& Umeasiegbu, B. (2013). The relationship between housing accessibility variables and employment status among adults with multiple sclerosis. Journal of Rehabilitation, 79(4), 4-14.

Chiu, C., Chan, F., Bishop, M., DaSilva Cardosa, E., \& O'Neill, J. (2013). State vocational rehabilitation services and employment in multiple sclerosis. Multiple Sclerosis Journal, 19, 1655-1664

Dillman, D. (2007). Mail and internet surveys (2nd ed.). Hoboken, NJ: John Wiley.

Fraser, R., Clemmons, D., Gibbons, L., \& Koepnick, D. (2009). Predictors of vocational stability in multiple sclerosis. Journal of Vocational Rehabilitation, 31, 129-135. 
Graves, W. H. (1991). Participatory action research: A new paradigm for disability and rehabilitation research. ARCA, 19, 8-10.

Honarmand, K., Akbar, N., Kou, N., \& Feinstein, A. (2011). Predicting employment status in multiple sclerosis patients: The utility of the functional composite. Journal of Neurology, 258(2), 244-249.

Johnson, K., Amtmann, D., Klasner, E., \& Kuehn, C. (2004). Medical, psychological, social and programmatic barriers to employment for people with multiple sclerosis. Journal of Rehabilitation, 70(1), 38-49.

Julian, L., Vella, L., Vollment, T., Hadjimichael, O., \& Mohr, D. (2008). Employment in multiple sclerosis: Exiting and reentering the work force. Journal of Neurology, 255, 1354-1360.

Knight, G. P., Roosa, M. W., Calderon-Tena, C. O., \& Gonzales, N. A. (2009). Methodological issues in research with Latino populations. In F. A. Villarruel, G. Carlo, J. M. Grau, M. Azmitia, N. J. Cabrera, \& T. J. Chahin (Eds.), Handbook of US Latino psychology: Developmental and community-based perspectives (pp. 45-62). Thousand Oaks, CA: Sage.

Krause, I., Kern, S., Horntrich, A., \& Ziemssen, T. (2013). Employment status in multiple sclerosis: Impact of disease-specific and non-disease specific factors. Multiple Sclerosis Journal, 19, 1792-1799.

Lakes ADA Center Legal Briefing, 3, 1-18.

Marini, I. (2003). What rehabilitation counselors should know to assist Social Security beneficiaries in becoming employed. Work: A Journal of Prevention, Assessment, and Rehabilitation, 21(1), 37-44.

Minden, S., Frankel, D., Hadden, L., Perloff, J., Srinath, K., \& Hoaglin, D. (2006). The Sonya Slifka Longitudinal Multiple Sclerosis Study: Methods and sample characteristics. Multiple Sclerosis, 12, 24-38.

Moore, P., Harding, K., Clarkson, H., Pickersgill, T., Wardle, M., \& Robertson, N. (2013). Demographics and clinical factors associated with changes in employment in multiple sclerosis. Multiple Sclerosis Journal, 19, 1647-1654.

Nissen, S., \& Rumrill, P. (2014). Employment and career development considerations. In B. Giesser (Ed.), Primer on multiple sclerosis (2nd ed.; pp. 362-391). New York, NY: Oxford University Press.

Phillips, L., \& Stuifbergen, A. (2006). Predicting continued employment in persons with multiple sclerosis. Journal of Rehabilitation, 72(1), 35-43.

Rivera, V., \& Landero, S. (2005). Multiple sclerosis in Mexican American population. International Journal of MS care, 7, 143147.

Roessler, R., \& Rumrill, P. (2015). Enhancing productivity on your job: The 'win-win' approach to reasonable accommodations. New York, NY: National Multiple Sclerosis Society.
Roessler, R., Rumrill, P., \& Hennessey, M. (2002). Employment concerns of people with multiple sclerosis: Building a national employment agenda. Kent, OH: Kent State University Center for Disability Studies, Report Submitted to the National Multiple Sclerosis Society.

Rumrill, P., Fraser, R., \& Johnson, K. (2013). Employment and workplace accommodation outcomes among participants in a vocational consultation service for people with multiple sclerosis. Journal of Vocational Rehabilitation, 39, 85-90.

Rumrill, P., Roessler, R., \& Koch, L. (1999). Surveying the employment concerns of people with multiple sclerosis: A participatory action research approach. Journal of Vocational Rehabilitation, 12(2), 75-82.

Rumrill, P., Roessler, R., McMahon, B., \& Fitzgerald, S. (2005). Multiple sclerosis and workplace discrimination: The national Equal Employment Opportunity Commission Americans with Disabilities Act research project. Journal of Vocational Rehabilitation, 23(3), 179-188.

Simmons, R., Tribe, K., \& McDonald, E. (2010). Living with multiple sclerosis: Longitudinal changes in employment and the importance of symptom management. Journal of Neurology, 257, 926-936.

Smith, M., \& Arnett, P. (2005). Factors related to employment status changes in individuals with multiple sclerosis. Multiple Sclerosis, 11, 602-609.

Sweetland, J., Riazi, A., Cano, S., \& Playford, E. (2007). Vocational rehabilitation services for people with multiple sclerosis: What patients want from clinicians and employers. Multiple Sclerosis, 13, 1183-1189.

Taylor, B. (2007). Reassignment as a reasonable accommodation under the ADA. Great Lakes ADA Center Legal Briefing, 3, $1-18$.

The HR Specialist. (2013). ADA accommodations may not be possible, but you must explore the options. Retrieved from www.theHRSpecialist.com

Uccelli, M., Specchia, C., Battaglia, M., \& Miller, D. (2009). Factors that influence the employment status of people with multiple sclerosis: A multi-national study. Journal of Neurology, 256, 1989-1996.

Vickers, M. (2012). Antenarratives to inform health care research: Exploring workplace illness disclosure for people with multiple sclerosis (MS). Journal of Health and Human Services Administration, 35, 170-206.

Wickert, K., Dresden, D., \& Rumrill, P. (2013). The sandwich generations' guide to eldercare. New York, NY: Demos. 